\title{
Tourism Attraction and Tourist Satisfaction with World Heritage: A Case Study of Mount Wuyi
}

\author{
Peihua Zhao \\ Shantou University \\ Liuqin Zhang \\ Shantou University \\ Robert Guang Tian (Corresponding Author) \\ Shantou University
}

This paper takes Mount Wuyi - a world natural and cultural heritage site - as an example. It collects data through questionnaires, employs factor analysis to explore tourism attraction of world heritage and adopts the ologit model for regression analysis of tourist satisfaction. The results show: firstly, world heritage brand significantly enhances the attractiveness of tourist attractions. Secondly, natural landscape, tea culture, ecological environment, accommodation, transportation, ticket price, staff service quality and world heritage brand all significantly and positively influence tourists' overall satisfaction while cultural relics, security conditions and individual characteristics have no significant impact. Finally, this paper puts forward some suggestions about the construction and management for Mount Wuyi.

\section{INTRODUCTION}

As of July 2017, when Hoh Xil and Kulangsu were included in the world heritage list by the 41 st session of the World Heritage Committee, China had had 52 world heritage sites, second only to Italy (53 sites). The abundant world heritage resources have laid a solid foundation for the vigorous development of China's heritage tourism. As a key component of the tourism industry, heritage tourism occupies a prominent position 41st in domestic and international tourism industries (Markwell et al., 1997; Guo Zhan, 2002).

UNESCO initially established the world heritage list to protect world natural and cultural sites. Lots of sites apply for world heritage status every year to seek adequate protection or attract tourists through the world heritage label (Poria et al., 2011). World heritage not only improves the image of tourism destinations, but also enhances their popularity by brand scarcity (Markwell et al., 1997). World heritage has been widely used as a tool to attract tourists in tourism destination promotion, both at home and abroad.

Tourism destinations should not only have strong attraction to tourists, but also provide them with high-quality tourism experience, and then enhance tourist satisfaction. Tourist satisfaction, which has 
been considered as an important business objective, is proportional to the revisiting intention of tourists. In other words, tourists with higher satisfactions are more willing to revisit these places and recommend them to their relatives and friends (Hui et al., 2007), so tourist satisfaction indirectly influence the future number of tourists. Since tourist satisfaction is proved to be the most important indicator to analyze tourist behavior (Dunnross \& Isoahola, 1991; Mansfeld, 1992), the improvement of tourist satisfaction is of paramount importance to the sustainable development of tourism destinations. Tourist satisfaction represents tourists' evaluation of tourism resources (natural landscapes, historical culture, etc.) and service quality in tourism destinations to a certain extent. It serves as a reliable indicator and facilitates the management of tourism destinations.

This paper studies and analyzes the relations between world heritage and tourism attraction, and those between world heritage brand and tourist satisfaction, taking Mount Wuyi - a world cultural and natural heritage site - as an example. As a unique and authoritative label, world heritage is expected to attract lots of tourists and enhance the attractiveness of tourism destinations. The emotion appraisal theory shows that tourists' positive cognition and evaluation of world heritage affect their overall satisfaction with world heritage sites (Bagozzi et al., 1999). Considering the heterogeneity of individual tourism demands, individual characteristics are introduced for analysis. Therefore, this research establishes a comprehensive understanding of influence factors on tourists' overall satisfaction and provides substantive suggestions for the construction and management of Mount Wuyi.

\section{LITERATURE REVIEW AND RESEARCH HYPOTHESIS}

\section{Impact of World Heritage Brand}

The impact of world heritage brand on tourism destinations should not be neglected. World heritage is an important business card for tourism destinations (Hall \& Piggin, 2002; Timothy, 2011; Yang et al., 2010). Tourism destinations labeled as world heritage sites tend to have distinct landscapes or culture and can stand out from the numerous tourism destinations. The world heritage title attracts lots of tourists to tourism destinations (Fyall, 2006; Shackley, 1998) and makes tourism destinations must-see places for a growing number of tourists (Li et al., 2008; Poria et al., 2013), which directly influences the selection of tourism destinations and enhances the attractiveness and competitiveness of tourism destinations (Poria et al., 2011; Su \& Lin, 2014). It gives the staff of tourism destinations a sense of pride and attracts lots of volunteers (Aa et al., 2004).

Tourism image refers to tourists' subjective perception of tourism destinations (Crompton, 1979). Since tourist image is closely related to tourist behavior, a popular tourism image increases the possibility of tourists to visit, revisit and recommend the tourism destinations to others (Crompton, 1979; Crompton \& Ankomah, 1993; Enrique Bigné et al., 2001). Liu Changxue (2005) analyzed world heritage sites Xidi and Hongcun from the perspective of push and pull factors and argued that cultural resources and distinct tourism images of vernacular villages played important roles in attracting tourists. There is no doubt that world heritage (an important part of the image of tourism destinations) will strengthen the image of tourism destinations and increase tourist expectations to a certain extent, based on which the following hypothesis is raised:

\section{$\boldsymbol{H}_{1}:$ World heritage band has a positive impact on the attractiveness of tourism destinations.}

\section{Tourist Satisfaction}

Tourist satisfaction is an attitude construct that refers to the perceptive evaluation of tourists on tourism experience (Neal \& Gursoy, 2008). Since tourist satisfaction affects the selection of tourism destinations, the revisiting intentions and the recommending intentions, it has been a research focus on

tourist behaviors. Tourist satisfaction can be further divided into overall satisfaction and attribute satisfaction. Wherein, overall satisfaction is the overall perception and evaluation of tourism experience while attribute satisfaction is the perceptive evaluation of tourists on the attributes of tourism destinations 
(Oliver, 1993), including natural landscapes, cultural landscapes, accommodation, environmental health and transportation (Oliver, 1993).

Tourism resources are the material basis for spatial competition of tourism destinations (Zhang Jinhe $\&$ Zhao Yong, 2004) and the lifeblood of tourism destinations. They not only include natural and cultural landscapes, but also cover software and hardware facilities around and inside tourism destinations (Yale, 1997). As a world natural and cultural heritage site, Mount Wuyi enjoys unique natural landscapes, historical and cultural relics and profound tea culture, indicating that tourists mostly visit Mount Wuyi to experience natural beauty, historical and cultural relics and tea culture. Therefore, these three factors are considered as important components of tourists' overall satisfaction. In addition, tourists' evaluation of local ecological environment, ticket price, accommodation and transportation also has a significant impact on their overall satisfaction (Hui et al., 2007; Song \& Cheung, 2010; Zhou Yang et al., 2016). However, there is still no unanimous consensus on this issue in academia, which is attributed to the different research objects. In other words, tourism destinations differ from each other in characteristics. Hui et al (2007) considered urban convenience, price, accommodation, tourist attraction and culture when studying tourist satisfaction in Singapore, and drew the following conclusions: the impact of each attribute on the overall satisfaction differs among tourists from different countries. Chi \& Qu (2008) selected Eureka Springs of Arkansas as the research object to study the relations between tourism destination image and tourist satisfaction, and adopted structural equation model to explore the impacts of transportation, tourist attraction, environment and accommodation on tourists' overall satisfaction. The results show that each of attribute satisfaction has a significant positive impact on overall satisfaction. Therefore, this paper takes natural landscape, historical and cultural relic, tea culture, ecological environment, transportation and accommodation as the influence factors on tourists' overall satisfaction for analysis and makes the following hypotheses:
$\boldsymbol{H}_{2-1}:$ Natural landscape has a positive impact on tourists' overall satisfaction.
$\boldsymbol{H}_{2-2}$ : Historical and cultural relic has a positive impact on tourists' overall satisfaction.
$\boldsymbol{H}_{2-3}:$ Tea culture has a positive impact on tourists' overall satisfaction.
$\boldsymbol{H}_{2-4}$ : Ecological environment has a positive impact on tourists' overall satisfaction.
$\boldsymbol{H}_{2-5}$ : Transportation has a positive impact on tourists' overall satisfaction.
$\boldsymbol{H}_{2-6}$ : Accommodation has a positive impact on tourists' overall satisfaction.

As a theory to explain emotional experience of tourists, the emotion appraisal theory has been gradually valued by scholars and applied to researches on the relations between tourism destination image and tourist behavior (Breitsohl \& Garrod, 2016; Hosany , 2012). The emotion appraisal theory holds that emotion represents the cognitive evaluation of individuals on external environment and individual interpretation of a situation causes an emotional response that is based on that interpretation (Bagozzi et al., 1999). Tourism image, which is a subjective perception of tourists, significantly influences emotional image of tourism destinations (Wang Chunyang \& Qu Hailin, 2013), thereby indirectly influencing tourists' overall satisfaction. Zhang et al. (2014) pointed out that tourism image had a direct and positive impact on tourist satisfaction. In other words, a popular tourism image enhances tourist satisfaction. The same as tourism experience, tourism image influences tourists' evaluation of tourism destinations (Chon, 1991; Ross, 1993). World heritage is defined by UNESCO as rare and currently irreplaceable wealth that has outstanding significance to human beings. Tourists tend to show curiosity and reverence for the title world heritage. According to the emotion appraisal theory, tourists' overall satisfaction with world heritage sites shall be influenced by their previous perception of world heritage, based on which the following hypothesis is raised:

\section{$\boldsymbol{H}_{3}:$ World heritage brand has a positive impact on tourists' overall satisfaction.}

Tourists' overall satisfaction is influenced by multiple factors, including individual characteristics (Ryan, 1997). Tourists with distinctive characteristics shall gain different experiences for the same service 
provided. Basic individual characteristics include gender, age, educational background and income. Tourists of different ages may differ greatly in aesthetic standards and world views, and tourists with different educational backgrounds have diverse cultural needs and cultural perceptions of Mount Wuyi. Income, which represents the economic capacity, is especially important. Income differences cause differences in tourists' needs for service quality to a certain extent. Some scholars have explored the impact of individual characteristics on tourist satisfaction and obtained different results. Li Shengling et al (2008) considered individual characteristics when analyzing tourist satisfaction with scenic park of Dr. Sun Yat-sen's Mausoleum in Nanjing, and found that tourists' age, monthly income and cultural background all influenced tourist satisfaction. Overall, tourists' age and monthly income were positively correlated with tourist satisfaction. Luo Wenbin et al (2013) identified the positive impact of monthly income on tourist satisfaction when exploring the relations between urban features and tourist satisfaction. They argued that high income often corresponded to strong consumption ability and high satisfaction. Lin Dan (2015) pointed out that educational background had a negative impact on tourist satisfaction in rural tourism and both income and source region of tourists affected tourist satisfaction. Yin Yan \& Zhou Yingheng (2013) studied rural tourism in southern Jiangsu and discovered that individual characteristics had no significant impact on tourist satisfaction. All these scholars used urban or rural non-heritage sites as the research objects. Since few scholars consider individual characteristics when researching tourist satisfaction with mountain heritage sites, it is of certain significance to incorporate individual characteristics into the researches on tourist satisfaction. This paper, which takes Mount Wuyi as the research object, holds that older tourists are more experienced, inclusive and satisfied with tourism destinations. In addition, tourists with higher educational background show greater demand for spiritual culture and tourism experience. In other words, highly-educated tourists are less satisfied than lowlyeducated tourists with the same tourism destination. The higher the monthly income, the stronger the consumption ability shall be, leads to larger freedom of consumption and higher satisfaction. On these bases, the following hypotheses are raised:

$\boldsymbol{H}_{4-1}:$ Age has a significant positive impact on tourists' overall satisfaction.

$\boldsymbol{H}_{4-2}$ : Educational background has a significant negative impact on tourists' overall satisfaction.

$\boldsymbol{H}_{4-3}:$ Monthly income has a significant positive impact on tourists' overall satisfaction.

\section{RESEARCH METHODS}

\section{Survey Region}

Mount Wuyi is in Wuyishan City of Fujian Province, with an area of 999.75 square kilometers. It enjoys unique natural landscapes and profound historical culture (tea culture, Confucian culture, Taoist culture and Buddhist culture). Major attractions of Mount Wuyi include Tianyou Peak, Jiuqu River, Dahongpao Scenic Spot and Shuilian Cave. Since Mount Wuyi is a national 5A-level scenic area in China and a world natural and cultural heritage site, this paper takes Mount Wuyi as the research object to comprehensively study tourism attraction and tourist satisfaction with world heritage.

\section{Research Data}

We randomly selected tourists at Mount Wuyi as the survey objects and conducted questionnaire surveys in September 2016. A total of 330 questionnaires were distributed, of which 283 were valid questionnaires (the effective rate: 85.76\%). The questionnaire participants consisted of $41 \%$ males and $59 \%$ females. In terms of age, participants under the age of 20, between 20 and 39 years old, between 40 and 59 years old and above the age of 60 accounted for $3.5 \%, 66.8 \%, 22.6 \%$ and $7.1 \%$ respectively. In terms of educational background, elementary and junior middle school students, high school students, secondary school students and technicians, junior college students, undergraduate students and graduate students accounted for $7.4 \%, 24.7 \%, 25.1 \%, 38.9 \%$ and $3.9 \%$ respectively. In terms of monthly income, participants with the income of 2000 Yuan and below, 2000 to 3999 Yuan, 4000 to 5999 Yuan, 6000 to 
7999 Yuan and 8000 Yuan and above accounted for $20.2 \%, 39.2 \%, 24.4 \%, 6.7 \%$ and $9.5 \%$ respectively. The participants were mostly young people, conforming to the distribution of tourists at Mount Wuyi.

The questionnaire consists of three parts. Wherein, Part 1 surveys individual characteristics, Part 2 investigates tourists' attitude toward world heritage brand and Part 3 explores tourists' evaluation of each tourism attribute. Both Part 2 and Part 3 use the five-point Likert scale, which indicates that each item is scored 1 (strongly disagree) to 5 (strongly agree).

\section{THE RESULTS}

\section{Brand Effect of World Heritage}

Part 2 of the questionnaire investigates tourists' attitude toward world heritage brand and involves a total of 17 items. Table 1 demonstrates basic statistical results of each item in the second part.

As can be seen from Table 1, almost all factors (excluding Factor 16) have a mean value greater than 3.5 , which indicates that world heritage has significant brand effects. In addition, all items with the mean value greater than 4 are indicative of positive brand effects of world heritage to a certain extent. Therefore, world heritage not only improves image of tourism destinations, but also promotes local economic development and cultural promotion and influences tourists' attitude toward tourism destinations, thus it can invisibly enhance the attractiveness of tourism destinations. Finally, negative effects of world heritage are manifested as the increased ticket prices and consumer prices.

TABLE 1

\section{STATISTICS OF TOURISTS' ATTITUDE TOWARD WORLD HERITAGE BRAND}

\begin{tabular}{lccc}
\hline & $\mathrm{N}$ & $\begin{array}{c}\text { Mean } \\
\text { Value }\end{array}$ & $\begin{array}{c}\text { Standard } \\
\text { Deviation }\end{array}$ \\
\hline 1. It's more likely to improve national or regional image. & 283 & 4.71 & 0.57 \\
2. It's able to attract more tourists. & 283 & 4.63 & 0.647 \\
3. It's able to become a tourism highlight of the country or region. & 283 & 4.51 & 0.791 \\
4. It enjoys unique natural landscapes and cultural relics. & 283 & 4.52 & 0.71 \\
5. It's worth visiting. & 283 & 4.41 & 0.769 \\
6. It's more attractive than other scenic spots in the region. & 283 & 4.04 & 0.961 \\
7. It's regarded as a must-see attraction. & 283 & 3.83 & 1.134 \\
8. I'm proud to have been here. & 283 & 3.83 & 1.115 \\
9. It's worth visiting again. & 283 & 3.64 & 1.188 \\
10. It strengthens my intention to visit here. & 283 & 3.88 & 1.047 \\
11. It enhances the brand value of Wuyi Mountain Rock Tea such & 283 & 4.34 & 0.909 \\
as Dahongpao Tea and Jinjunmei Tea. & & \\
12. It's conductive to the propagation and dissemination of Chinese & 283 & 4.49 & 0.811 \\
tea culture. & 283 & 4.53 & 0.734 \\
13. It shall prompt local economic development. & 283 & 4.51 & 0.745 \\
14. Living standards of nearby residents shall be improved. & & & 1.164 \\
15. People will purchase tea planted in Mount Wuyi at higher & 283 & 3.62 & \\
prices. & 283 & 2.74 & 1.404 \\
16. The ticket price can be appropriately raised. & 283 & 3.66 & 1.098 \\
17. People are willing to spend more money in coming here for \\
sightseeing.
\end{tabular}


We adopted factor analysis to extract common influence factors from these 17 factors, to further analyze tourists' attitude towards world heritage brand. The KMO and p value were 0.88 and 0.000 separately, indicating that the original variables were highly correlated and the factor analysis method was appropriate. 4 common influence factors with eigenvalues greater than 1 were yielded based on eigenvalue and scree plot, explaining $60.891 \%$ of the variance. Considering that this paper studied tourism attraction of world heritage, common factors could be correlated. As a result, oblique rotation method was employed.

As is shown in Table 2, a total of four common influence factors were extracted from the 17 original factors: "attracting people", "attracting me", "economy and culture" and "negative factor", among which "attracting people" and "attracting me" can be regarded as the impacts of world heritage brand on improving tourism attraction. The two factors explain $45 \%$ of the variance, and occupy important positions. "Economic significance" is manifested as the impact of world heritage brand on local economic development while "negative factor" is the least important common factor. In addition, the reliability test shows that all common factors have high Cronbach's alpha coefficients, which indicates the high reliability of common factors extracted. Thus, $\mathrm{H}_{1}$ was supported.

TABLE 2

FACTOR ANALYSIS OF WORLD HERITAGE BRAND EFFECTS

\begin{tabular}{|c|c|c|c|c|}
\hline & \multicolumn{4}{|c|}{ Factor } \\
\hline & $\begin{array}{l}\text { Attracting } \\
\text { People }\end{array}$ & $\begin{array}{l}\text { Attracting } \\
\mathrm{Me}\end{array}$ & $\begin{array}{l}\text { Economic } \\
\text { Significance }\end{array}$ & $\begin{array}{l}\text { Negative } \\
\text { Factor }\end{array}$ \\
\hline $\begin{array}{l}\text { It's more likely to improve national or } \\
\text { regional image. }\end{array}$ & 0.736 & & & \\
\hline It's able to attract more tourists. & 0.761 & & & \\
\hline $\begin{array}{l}\text { It's able to become a tourism highlight of } \\
\text { the country or region. }\end{array}$ & 0.838 & & & \\
\hline $\begin{array}{l}\text { It enjoys unique natural landscapes and } \\
\text { cultural relics. }\end{array}$ & 0.74 & & & \\
\hline It's worth visiting. & 0.694 & & & \\
\hline $\begin{array}{l}\text { It's more attractive than other scenic spots } \\
\text { in the region }\end{array}$ & & 0.731 & & \\
\hline It's regarded as a must-see attraction. & & 0.729 & & \\
\hline I'm proud to have been here. & & 0.674 & & \\
\hline It's worth visiting again. & & 0.784 & & \\
\hline It strengthens my intention to visit here. & & 0.846 & & \\
\hline $\begin{array}{l}\text { It enhances the brand value of Wuyi } \\
\text { Mountain Rock Tea such as Dahongpao } \\
\text { Tea and Jinjunmei Tea. }\end{array}$ & & & 0.726 & \\
\hline $\begin{array}{l}\text { It's conductive to the propagation and } \\
\text { dissemination of Chinese tea culture. }\end{array}$ & & & 0.77 & \\
\hline It shall prompt local economic & & & 0.782 & \\
\hline $\begin{array}{l}\text { Living standards of nearby residents shall } \\
\text { be improved. }\end{array}$ & & & 0.78 & \\
\hline
\end{tabular}


People are willing to spend more money in coming here for sightseeing.

The ticket price can be appropriately

People will purchase tea planted in Mount Wuyi at higher prices.

0.798

Eigenvalue

Percentage of Explained Variance

$$
6
$$

$35.297 \%$

1.713

1.596

1.042

Cronbach's Alpha

0.808

$10.079 \%$

$9.387 \%$

$6.128 \%$

Mean Factor Value

4.542

0.816

0.779

0.664

Extraction Method: principle component analysis; Rotation Method: Kaiser oblique rotation

\section{Tourists' Overall Satisfaction}

Stata12.0 software was employed for regression processing of the data. We selected "tourists' overall satisfaction" as the dependent variable, and used "attribute satisfaction", "individual characteristics" and "world heritage brand" as independent variables. Wherein, the independent variable "world heritage brand" was obtained through the above analysis while the common factor "attracting me" was averagely processed into the variable "world heritage brand". Since the dependent variable "tourists' overall satisfaction" was discrete data with ordered nature, an ordered regression model was adopted for analysis. Ordered regression model can be divided into oprobit model and ologit model and the two models merely differ in the distribution of independent variables, and being used interchangeably in econometric. Therefore, we introduced the ologit model for robust regression and the results in Table 3.

TABLE 3

\section{OLOGIT MODEL FOR TOURISTS' OVERALL SATISFACTION}

\begin{tabular}{|c|c|c|}
\hline & Model 1 & Model 2 \\
\hline Natural Landscape & $0.725 * * \quad(2.42)$ & $0.755^{* *}(2.51)$ \\
\hline Historical and Cultural & $0.255 \quad(1.12)$ & $0.230 \quad(1.01)$ \\
\hline $\bar{T}$ ea Culture & $0.509 * *(2.32)$ & $0.552 * *(2.45)$ \\
\hline Ecological Environment & $0.496 * * \quad(2.18)$ & $0.527 * *(2.14)$ \\
\hline Accommodation & $0.328 * \quad(1.90)$ & $0.337 *(1.91)$ \\
\hline Transportation & $0.503 * * *(2.60)$ & $0.463 * *(2.36)$ \\
\hline Security & $0.1000 \quad(0.41)$ & $0.0894 \quad(0.37)$ \\
\hline Ticket Price & $0.531 * * *(2.91)$ & $0.493 * *(2.57)$ \\
\hline Staff Service & $0.505^{* *}(2.28)$ & $0.512 * *(2.30)$ \\
\hline World Heritage Brand & $0.438 * * \quad(2.02)$ & $0.448 * *(2.00)$ \\
\hline Age & & $0.262 \quad(1.08)$ \\
\hline Educational Background & & $-0.0573(-0.40)$ \\
\hline Monthly Income & & $0.0656 \quad(0.48)$ \\
\hline Pseudo R2 & 0.3896 & 0.3928 \\
\hline Log pseudolikelihood & -175.5565 & -174.63016 \\
\hline Wald chi2 & 85.75 & 89.02 \\
\hline $\mathrm{P}$ & 0.0000 & 0.0000 \\
\hline $\mathrm{N}$ & 283 & 283 \\
\hline
\end{tabular}


In Table 3, Model 1 is the regression model of relations between attribute satisfaction and overall satisfaction while Model 2 is the regression model included individual characteristics based on Model 1. Both Model 1 and Model 2 passed the significance test and $\mathrm{R}^{2}$ for both models approached 0.4, indicating that the models were statistically significant.

According to the regression results, natural landscape, tea culture, ecological environment, transportation, accommodation and world heritage brand all significantly affect tourists' overall satisfaction. Therefore, $\mathrm{H}_{2-1}, \mathrm{H}_{2-3}, \mathrm{H}_{2-4}, \mathrm{H}_{2-5}, \mathrm{H}_{2-6}$ and $\mathrm{H}_{3}$ were supported while $\mathrm{H}_{2-2}, \mathrm{H}_{4-1}, \mathrm{H}_{4-2}$ and $\mathrm{H}_{4-3}$ were not. In addition, ticket price and staff service quality were found to have a significant positive impact on tourists' overall satisfaction.

As a typical natural and cultural scenic area, Mount Wuyi takes natural and cultural landscapes as the core tourism resources. According to the regression analysis, the coefficients of natural landscape and tea culture on tourists' overall satisfaction were 0.725 and 0.509 respectively, which is consistent with the reality of Mount Wuyi. It was unexpected that historical and cultural relics had no significant impact on tourist satisfaction, though the coefficient was 0.255 . This is attributed to the structural characteristics of tourists at Mount Wuyi. Mount Wuyi belongs to mountain-type natural and cultural scenic spots and differs from cities, plain lakes and museums. Since it is time-consuming for old-aged or busy tourists to visit Mount Wuyi, tourists at Mount Wuyi are mostly young and middle-aged people with moderate income. Sample structure of this paper is basically the same as that of Su Lujun \& Huang Fucai (2010), indicating that the research sample conforms to the reality of tourists at Mount Wuyi. Due to the difference in life experience, the understanding of historical and cultural relics differs greatly among young, old and middle-aged people. In comparison with old people, young and middle-aged people attach more importance to the sensory stimulation of natural landscapes and tea culture.

The coefficient of ecological environment on tourists' overall satisfaction was statistically significant (0.496). Ecological environment of tourism destinations is closely linked with tourism experience. Better ecological environment represents better afforestation and environmental condition and provides tourists with more comfortable tourism experience, thereby enhancing their overall satisfaction. In addition, transportation and accommodation also exerted a significant impact on tourists' overall satisfaction and the coefficients were 0.503 and 0.328 separately. Transportation determines the degree of difficulty for tourists' journey while accommodation affects tourism experience, they are influence tourism comfort and overall satisfaction of tourists.

World heritage brand significantly influenced tourists' overall satisfaction and the coefficient was 0.438 , which indicates that world heritage brand significantly enhances tourists' overall satisfaction. World heritage itself is authoritative and almost all tourists hold a positive attitude toward world heritage. Therefore, tourists' overall satisfaction with world heritage sites shall be influenced by their previous perception of world heritage, which verifies the scientific rationality of applying the emotion appraisal theory to tourism management.

Finally, the coefficients of ticket price and staff service quality were 0.531 and 0.505 separately. Tourists not only pay great attention to tourism experience, but also attach immense importance to travelling expenses. Better staff service quality leads to more comfortable tourism experience while more favorable ticket price corresponds to lower consumption, all improving tourist satisfaction.

Although the regression result in Model 2 indicate that the impacts of individual characteristics are in line with the hypotheses, their coefficients are not significant, indicating that individual characteristics have no significant impact on natural and cultural heritage sites such as Mount Wuyi. This paper holds that Mount Wuyi differs from urban landscapes which provides varied high-quality service for diverse types of tourists. There is slight difference between services provided by Mount Wuyi, which weakens the impacts of individual characteristics on tourist' overall satisfaction. 


\section{CONCLUSION AND RECOMMENDATION}

This paper collects data through questionnaires and explores the relations between world natural and cultural heritage and tourist satisfaction with empirical research. The results show: world natural and cultural heritage enhances the attractiveness of tourism attractions and significantly positively influences the overall satisfaction of tourists. In other words, world heritage brand not only affects tourism destination selection, attracts tourists, promotes local tourism and boosts local economic development, but also arouses positive emotions and enhances tourists' overall satisfaction. Hence world heritage brand indirectly influences tourist behaviors (recommending and revisiting). Research results in this paper are consistent with those of existing researches on world natural or cultural heritage (Poria et al., 2011; Poria et al., 2013), which explains why the various countries (including China) actively apply for world heritage status to a certain extent.

Natural landscape, tea culture and ecological environment all have a significant impact on the tourist satisfaction with world natural and cultural heritage sites. Mount Wuyi, which is a combination of natural and cultural landscapes, takes natural landscapes, tea culture and cultural relics as the core tourism resources. Therefore, priority should be given to the protection of natural landscapes and ecological environments. Firstly, the scenic area should be developed and constructed in accordance with the law of nature so as not to exert a negative impact on natural ecological environment. Secondly, the scenic area should enhance the propagation of tea culture trough various effective means while adopting powerful measures to protect rare and ancient tea tree species. For example, it could hold "tea competition", organize "tea expo" and promote tea culture through the Internet. Although it is revealed in this paper that cultural relics have no significant impact on tourist satisfaction, it is unwise to leave the historical and cultural relics in Mount Wuyi unattended. It can be show that little attention is paid to the exploration and propagation of historical culture, and these are things Mount Wuyi needs to be improved and requires large effort to work. Mount Wuyi, which has been rated by UNESCO as a world natural and cultural heritage site, is one of the four dual heritage sites in China. Governments should reflect why people are impressed by the natural landscapes of Mount Wuyi, rather than the cultural relics.

Both transportation and accommodation significantly and positively influence tourist satisfaction. Transportation determines the degree of difficulty for tourists' journey while accommodation affects tourism experience, which are indirectly influence psychological state and overall satisfaction of tourists. Local governments should actively strengthen the infrastructure construction of surrounding transportation facilities and improve the transportation systems, which is crucial to the development of local tourism.

\section{REFERENCES}

Aa, B. J. M. V., Groote, P. D. \& Huigen, P. P. P. (2004). World heritage as NIMBY? The case of the Dutch part of the Wadden Sea. Current Issues in Tourism. 7, 291-302.

Bagozzi, R. P., Gopinath, M. \& Nyer, P. U. (1999). The role of emotions in marketing. Journal of the Academy of Marketing Science. 27, 184.

Breitsohl, J. \& Garrod, B. (2016). Assessing tourists' cognitive, emotional and behavioral reactions to an unethical destination incident. Tourism Management. 54, 209-220.

Chi, G. Q. C. \& Qu, H. L. (2008). Examining the structural relationships of destination image, tourist satisfaction and destination loyalty: an integrated approach. Tourism Management. 29, 624-636.

Chon, K. S. (1991). Tourism destination image modification process: marketing implications. Tourism Management. 12, 68-72.

Crompton, J. L. (1979). An assessment of the image of Mexico as a vacation destination and the influence of geographical location upon that image. Journal of Travel Research. 17, 18-23.

Crompton, J. L., \& Ankomah, P. K. (1993). Choice set propositions in destination decisions. Annals of Tourism Research. 20, 461-476. 
Dunnross, E. L., \& Isoahola, S. E. (1991). Sightseeing tourists' motivation and satisfaction. Annals of Tourism Research. 18, 226-237.

Enrique Bigné, J., Isabel Sánchez, M. \& Sánchez, J. (2001). Tourism image, evaluation variables and after purchase behavior: inter-relationship. Tourism Management. 22, 607-616.

Fyall, A. (2006). The future market for World Heritage Sites. Managing world heritage sites, ButterworthHeinemann, Oxford, UK.

Guo, Z. (2002). Some considerations on the relationship between world heritage and tourism. Tourism Tribune. 17, 5-6.

Hall, C. M., \& Piggin, R. (2002). Tourism business knowledge of World Heritage sites: A New Zealand case study. International Journal of Tourism Research. 4, 401-411.

Hosany, S. (2012). Appraisal Determinants of Tourist Emotional Responses. Journal of Travel Research. 51, 303-314.

Hui, T. K., Wan, D., \& Ho, A. (2007). Tourists' satisfaction, recommendation and revisiting Singapore. Tourism Management. 28, 965-975.

Li, M., Wu, B., \& Cai, L. P. (2008). Tourism development of World Heritage Sites in China: a geographic perspective. Tourism Management. 29, 308-319.

Li, S. L., Ren, L., Liao, N. \& Gu, J. (2008). Study on tourist satisfaction in by fuzzy evaluation - a case study of Dr Sun Yat-sen's Mausoleum Scenic Area in Nanjing. Henan Sciences. 26, 1426-1430.

Lin, D. (2015). Empirical study about the influencing factors of rural tourist satisfaction based on factor analysis and single factor analysis of variance. Journal of Central South University of Forestry \& Technology (Social Sciences). 9, 56-60.

Liu, C. X. (2005). A study of push and pull factors at world heritage sites - a case of vernacular villages Xidi and Hongcun in Southern Anhui. Tourism Tribune. 20, 15-20.

Luo, W. B., Xu, F. X., Timothy, D.J., \& Huang,Y. N. (2013). An analysis of factors influencing the satisfaction of urban visitors: city features, personal characteristics and tourist motives. Tourism Tribune. 28, 50-58.

Mansfeld, Y. (1992). From motivation to actual travel. Annals of Tourism Research. 19, 399-419.

Markwell, S., Bennett, M., \& Ravenscroft, N. (1997). The changing market for heritage tourism: A case study of visits to historic houses in England. International Journal of Heritage Studies. 3, 95-108.

Neal, J. D., \& Gursoy, D. (2008). A multifaceted analysis of tourism satisfaction. Journal of Travel Research. 47, 53-62.

Oliver, R. L. (1993). Cognitive, Affective, and Attribute Bases of the Satisfaction Response. Journal of Consumer Research. 20, 418-430.

Poria, Y., et al. (2011). World Heritage Site - is it an effective brand name? A case study of a religious heritage site. Journal of Travel Research. 50, 482-495.

Poria, Y., Reichel, A., \& Cohen, R. (2013). Tourists perceptions of World Heritage Site and its designation. Tourism Management. 35, 272-274.

Ross, G. F. (1993). Destination evaluation and vacation preferences. Annals of Tourism Research. 20, 477-489.

Ryan, C. (1997). The tourist experience: a new introduction, Cassell, London.

Shackley, M. (1998). Visitor management: case studies from world heritage sites. Oxford: ButterworthHeinemann.

Song, H. Q., \& Cheung, C. (2010). Factors affecting tourist satisfaction with theatrical performances: a case study of The Romance of the Song Dynasty in Hangzhou, China. Journal of Travel \& Tourism Marketing. 27, 708-722.

Su, L. J., \& Huang, F. C. (2010). A study of service fairness mechanism on tourist loyalty: a case study of sightseeing tourists at Wuyi Mountain. Tourism Science. 24, 26-39.

Su, Y. W., Lin, H. L. (2014). Analysis of international tourist arrivals worldwide: The role of world heritage sites. Tourism Management. 40, 46-58.

Timothy, D. J. (2011). Cultural heritage and tourism: an introduction. Cultural Heritage \& Tourism an Introduction. 2, 123-126. 
Wang, C. Y., \& Qu, H. L. (2013). Empirical study on relationships of travel motivation, destination image and tourist expectation. Tourism Tribune. 28, 26-37.

Yale, P., (1997). From tourist attractions to heritage tourism. ELM Publications, Huntingdon.

Yang, C. H., Lin, H. L., \& Han, C. C. (2010). Analysis of international tourist arrivals in China: The role of World Heritage Sites. Tourism Management. 31, 827-837.

Yin, Y., \& Zhou, Y. H. (2013). A study of the influence factors of rural tourist satisfaction: based on the comparison of different types of tourist destinations. Social Sciences in Nanjing. 146-153.

Zhang, H. M., Fu, X. X., Cai, L. A., \& Lin, L. (2014). Destination image and tourist loyalty: a metaanalysis. Tourism Management. 40, 213-223.

Zhang, J. H., \& Zhao, Y. (2004). Analysis on the Spatial Structure of Tourism Resources in the South of Anhui Province. Geography and Geo-Information Science. 20, 99-103.

Zhou, Y., He, J. H. \& Rong, H. (2016). Tourist satisfaction in China's rural tourism and its influencing factors. Economic Management Journal. 156-166. 